ORIGINAL ARTICLE

\title{
Role of Tranexamic Acid for Seroma Prevention in Obese Patients Undergoing Laparoscopic Ventral Hernia Repair Under Spinal Anesthesia
}

RIZWAN KHAN ${ }^{1}$, MAHABUB AALAM ${ }^{2}$, NAEEM AHMED ${ }^{3}$, MUDDASAR PERVAIZ ${ }^{4}$, ZAHID SAEED ${ }^{5}$

${ }^{1}$ Consultant Surgeon, Jinnah Postgraduate Medical Centre (JPMC), Karachi

${ }^{2}$ Medical officer Emergency \& General Ward at Dinkar hospital sarlahi PVT. LTD. Nepal

${ }^{3}$ Consultant General and Laparoscopic Surgeon, Midland Doctors Medical Institute Tandali, Muzaffarabad

${ }^{4}$ Assistant Professor in Community medicine department, Al-Nafees Medical College, Islamabad

${ }^{5}$ Assistant Professor of Surgery, Mohi ud Din Islamic Medical college Mirpur Azad Kashmir

Corresponding author: Rizwan Khan, Email: drrizwankhan179@gmail.com, Cell: 0302-2797727

\begin{abstract}
Objective: The aim of this study is to determine the effectiveness of tranexamic acid for seroma prevention in obese patients undergoing laparoscopic ventral hernia repair under spinal anesthesia.

Study Design: Cross sectional study

Place and Duration: Jinnah Postgraduate Medical Center (JPMC) Karachi, 1st July 2020 to 30th June 2021.

Methods: There were one hundred and ten patients $f$ both genders had abdominal hernia were included in this study. We have taken written consent from all the patients for detailed demographics age, sex and body mass index. Patients were undergone for laparoscopic ventral hernia repair under spinal anesthesia in OPD. The size and contents of the defect were determined by an abdominal and pelvic ultrasound. All patients received postoperative tranexamic acid. Drains were put in to measure the amount of seroma that was produced as a result of the procedure. SPSS 22.0 was used to analyze all of the data.

Results: $42.23 \pm 6.55$ years were the mean age of the patients. Mean Body mass index was $32.13 \pm 3.43 \mathrm{~kg} / \mathrm{m}^{2}$. Majority of the patients $74(67.3 \%)$ were females and rest of the patients $36(32.7 \%)$ were males. In $91(82.7 \%)$ cases seroma reduction was calculated within week. Only 41 of the 110 patients had drain output of less than $150 \mathrm{ml}, 55$ had drain output of 150-300 ml, and 14 had drain output greater than $300 \mathrm{ml}$. Seroma formation was found among 7 (6.4\%) cases.

Conclusion: Tranexamic acid was found to be efficient in minimizing postoperative seroma formation in ventral hernia repairs, according to the findings of this study.

Keywords: Laparoscopic, Tranexamic acid, Plasminogen, Seroma, Obese Patients
\end{abstract}

\section{INTRODUCTION}

Abdominal hernias are caused by flaws in the abdominal wall that allow some or all of the contents of the abdominal cavity to bulge out of the compromised abdominal area. Between the thorn and the hips, these hernias can occur anywhere in the abdominal cavity. Operative practise is the most prevalent method of hernia repair. Seromas are more likely to form in people who have undergone extensive surgery, such as the repair of an abdominal hernia mesh. Additionally, the use of anticoagulants and prior surgical history, as well as the formation of seromas, are other risk factors for thromboembolism. [2] After paraumbilical hernioplastic fluids, which are also known as serum fluids, a seroma is a fluid buildup in the tissue that can occur in the adjacent blood and lymphatic vessels. The fluid in which cells are often found is usually transparent. Risk of infection and surgical site disturbance are possible causes of seromas. Surgical drain tubes are used after certain procedures to limit the risk of seroma formation. Flow volume can be adjusted, and drainage is eliminated when it reaches a predetermined level. When drains are not used and when drains are removed during surgery, seromes may form. Even while they can always be solved on their own, little seromas can also calcify hard nodes without being addressed. A needle is typically used to remove fluid from larger seromas, which necessitates an aspiration procedure. On rare situations, antibiotics may be needed to treat infected seromas, and in other cases, surgery may be necessary. Patients' risks of seroma development are minimised, and potential consequences are avoided, by surgeons using a variety of tactics. In order to achieve its anti-fibrinolytic action, tramexamic acid blocks lysine binding sites on the molecules of plasminogen, hence limiting the conversion of plasminogen to plasmin. This reversible blocking of these binding sites is what gives tramexamic acid its antifibrinolytic activity. [5] As a result, hemostatic fibrin is prevented from dissolving, stabilising the fibrin structure and reducing the formation of seroma at the site of dissection. [6]

Patients are protected from future difficulties and the possibility of seroma formation by utilising a variety of surgical procedures. In order to achieve its anti-fi brinolytic effect, Tranexamic acid acts by blocking lysine-binding sites on plasminogen molecules, hence decreasing the conversion of plasminogen to the active plasminogen. The hemostatic fi brin is thus prevented from dissolving, stabilising its structure and reducing the formation of seroma at the dissection site. [8,9]

In the main or secondary stages of wound healing, excessive bleeding is prevented and treated using tranexamic acid, a synthetic derivative of lysine that acts as an anti-fibrinolytic. Surgical bleeding can occur despite the use of bleeding control measures when fibrinolysis exceeds coagulation. In order to prevent fibrinolysis, tranexamic acid is administered. It keeps plasminogen from becoming plasmin. A whopping $34 \%$ of patients who use it have less postoperative bleeding after surgery. $[10,11]$ Transexamic acid has been shown to be an effective method for preventing seroma following surgical repair.

\section{MATERIAL AND METHODS}

This cross-sectional study was conducted at Jinnah Postgraduate Medical Center (JPMC) Karachi and comprised of 110 patients. We have taken written consent from all the patients for detailed demographics age, sex and body mass index. Liver disease, strangulation hernias, uncontrolled diabetes and bleeding problems were all ruled out of the study.

A thorough medical history and examination were conducted. Investigations at the lab centred on anaesthesia and surgery. The size and contents of the defect were determined by an abdominal and pelvic ultrasound. Informed consent and anaesthesia fitness were assessed. The usual surgical onlay mesh repair was given to all patients. In order to monitor the volume of seroma, an air vacuum drain was put in place Tranexamic acid was administered intravenously at the time of skin closure and subsequently by mouth every 12 hours until the 7th postoperative day. The daily outflow of the drain was recorded. As soon as wound drainage was less than $30 \mathrm{ml}$ in 24 hours, or on the seventh postoperative day, the drain was taken out. The numerical and categorical data were presented using descriptive statistics. The findings were sorted by age and gender, as well. The Chi-square test was employed to determine statistical significance after stratification. A P-value of less than 0.05 was considered significant. SPSS 22.0 was used to analyze all of the data. 


\section{RESULTS}

$42.23 \pm 6.55$ years were the mean age of the patients. Mean Body mass index was $32.13 \pm 3.43 \mathrm{~kg} / \mathrm{m}^{2}$. Majority of the patients 74 $(67.3 \%)$ were females and rest of the patients $36(32.7 \%)$ were males.(Table 1)

Table 1: Demographics detailed of enrolled cases

\begin{tabular}{|l|c|l|}
\hline Variables & Frequency & Percentage \\
\hline Mean age (years) & $42.23 \pm 6.55$ & \\
\hline Mean BMI (kg/m²) & $32.13 \pm 3.43$ & \\
\hline Gender & $74(67.3 \%)$ & 67.3 \\
\hline Male & $36(32.7 \%)$ & 32.7 \\
\hline Female
\end{tabular}

In $91(82.7 \%)$ cases seroma reduction was calculated within a week. Only 41 of the 110 patients had drain output of less than $150 \mathrm{ml}, 55$ had drain output of $150-300 \mathrm{ml}$, and 14 had drain output greater than $300 \mathrm{ml}$.(table 2)

Table 2: Post-operative effectiveness among enrolled cases

\begin{tabular}{|l|l|l|}
\hline Variables & Frequency & Percentage \\
\hline Serum Control & 91 & 82.7 \\
\hline$<7$ days & 10 & 17.3 \\
\hline$>7$ days & 41 & 37.3 \\
\hline Drain output & 55 & 50 \\
\hline$<150 \mathrm{ml}$ & 14 & 12.7 \\
\hline $150-300 \mathrm{ml}$ & \multicolumn{2}{|l|}{} \\
\hline$>300 \mathrm{ml}$ &
\end{tabular}

Table 3: Seroma formation was found among 7 (6.4\%) cases.(table 3)

\begin{tabular}{|l|l|l|}
\hline Variables & Frequency (110) & Percentage \\
\hline Seroma formation & 7 & 6.4 \\
\hline Yes & 103 & 93.6 \\
\hline No
\end{tabular}

\section{DISCUSSION}

Hernias can occur in a variety of places across the body. In most cases, these deformities affect the abdominal wall.[12] Ventral abdominal hernias are simply defined as a non-inguinal and nonhiatal defect in the abdominal wall's fascia. As many as $10 \%$ to $15 \%$ of all surgical procedures worldwide are hernia repairs. [13] After a laparotomy, the likelihood of developing a hernia is $10 \%$, after a muscle-splitting incision, $5 \%$, and less than $1 \%$ after a laparoscopic repair. Utako Okamoto made the discovery of tranexamic acid (TXA) in 1962. [14] Hemorrhage after significant trauma, postpartum bleeding, surgery, tooth removal, nose bleeding, and heavy menstruation can all be treated or prevented using this well-known medicine. Also, it has been included to the World Health Organization's list of essential medications. TXA is an affordable and cost-effective treatment in high, middle, and lowincome nations. It can be administered orally or intravenously. Tranexamic acid should be administered by gradual intravenous injection at a rate of $1 \mathrm{ml} /$ minute every 6 to 8 hours, or $15 \mathrm{mg} / \mathrm{kg}$ of body weight each ampoule of $10 \mathrm{ml}$ or 2 ampoule of $5 \mathrm{ml}$. [15] In patients with hepatic impairment, no dosage change is necessary, making it a safe treatment for those with chronic liver illness.

In this cross-sectional study one hundred and ten patients were presented. $42.23 \pm 6.55$ years were the mean age of the patients. Mean Body mass index was $32.13 \pm 3.43 \mathrm{~kg} / \mathrm{m}^{2}$. Majority of the patients $74(67.3 \%)$ were females and rest of the patients 36 $(32.7 \%)$ were males. Findings of current research were comparable to the studies conducted in past. $[16,17]$ Seromas are prevalent and usually emerge following different types of hernia repair especially those that are big and involve major tissue disturbance. The specific aetiology of seroma production remains disputed however it is assumed to be the collection of liquefied fat, serum, inflammatory exudates and lymphatic fluid under skin flap. The degree and duration of seroma production varies and influenced by several factors such extent of dissection and manner of lifting the skin flap such as electrocautery or knife. Untreated seromas usually become infectious. In 91 (82.7\%) cases seroma reduction was calculated within a week. Only 41 of the 110 patients had drain output of less than $150 \mathrm{ml}, 55$ had drain output of $150-300 \mathrm{ml}$, and 14 had drain output greater than $300 \mathrm{ml}$. Same comparable results were assessed in previous studies.[18,19] Seroma formation was found among 7 (6.4\%) cases.[19]

Tranexamic acid, a fibrinolytic medication, has been shown to reduce post-operative soakage, seroma formation, and serous fluid generation. It has been shown to aid in the healing of wounds. Tranexamic acid has also been shown to reduce the amount of seroma in our investigation. Using $1 \mathrm{~g}$ of tranexamic acid daily significantly lowered the mean postoperative drainage volume and shortened the mean hospital stay according to a randomized double-blind trial. The majority of participants in our study had a seroma lasting 8 days or less. Tranexamic acid appears to be the sole contributor to the decreased production of seroma. The results of another prospective randomized trial conducted by Gogna and Goyal P showed that tranexamic acid $1 \mathrm{~g}$ three times daily was effective in reducing seroma formation following modified radical mastectomy for breast cancer. The study included fifty breast cancer patients who underwent modified radical mastectomy with level III axillary clearance. The researchers found that tranexamic acid $1 \mathrm{~g}$ three times daily was effective in decreasing post-operative drainage volume when compared with placebo.[20]

In 81 percent of seroma patients, tranexamic acid subsides in the community within five days, and in 19 percent of patients, it takes more than five days. Anti-fibrinolytic medication tranexamic acid was found to reduce postoperative soakage, seroma, and serous fluid generation.[16] According to accounts, it aids in the healing of wounds. Seroma levels in our sample have likewise been reduced by tranexamic acid. There is also a significant reduction in post-operative drainage volume and hospital stay length when tranexamic acid $1 \mathrm{~g}$ per day is given to patients following surgery. [21] Tranexamic acid inhibits the production of post-operative seromas in patients undergoing mesh hernioplasty for a ventral hernia. As a result, drain removal after surgery is also reduced. Tranexamic acid in divided doses minimises the overall expense and morbidity of the patient, allowing them to return to their normal lives sooner.

\section{CONCLUSION}

Tranexamic acid was found to be efficient in minimizing postoperative seroma formation in ventral hernia repairs, according to the findings of this study.

\section{REFERENCE}

1 Ammar AA, Ismail T. Abdominal wall hernias in upper Egypt: A different spectrum. East Central Afr J Surg 2008:13:109-14.

2 Cho JE, Helm MC, Helm JH, Mier N, Kastenmeier AS, Gould JC, et al. Retrorectus placement of bio-absorbable mesh improves patient outcomes. Surg Endosc 2019;33:2629-34

3 Vlasov AV, Kukosh MV. The problem of wound complications in abdominal wall endoprosthesis replacement in ventral hernias. Sovremennye Tehnologii Med 2013;5(2):116-22.

4 Purushotham G, Revanth K, Aishwarya M. Surgical management of umbilical and paraumbilical hernias. Int Surg J 2017;4(8):2507-11

5 Vijay BS, Bedi V, Mitra S, Das B. Role of tranexamic acid in reducing postoperative blood loss and transfusion requirement in patients undergoing hip and femoral surgeries. Saudi J Anaesthesia 2013;7(1):29.

6 Gadre A, Stoller JK. Tranexamic acid for hemoptysis: a review. Clin Pulmonary Med 2017;24(2):69-74

7 Vijay BS, Bedi V, Mitra S, Das B. Role of tranexamic acid in reducing postoperative blood loss and transfusion requirement in patients undergoing hip and femoral surgeries. Saudi journal of anaesthesia. 2013 Jan;7(1):29.

8 Gadre A, Stoller JK. Tranexamic acid for hemoptysis: a review. Clinical Pulmonary Medicine. 2017 Mar 1;24(2):69-74.

9 Pabinger I, Fries D, Schöchl H, Streif W, Toller W. Tranexamic acid for treatment and prophylaxis of bleeding and hyperfi brinolysis. Wiener klinische Wochenschrift . 2017 May 1;129(9- 10):303-16

10 Ponten JEH, Somers KYA, Nienhuijs SW. Pathogenesis of the epigastric hernia. Hernia. 2012;16:627-33. 
11 Nixon SJ. Abdominal wall ernia and umbilicus. In:Williams NS Bulstrode CJK, O'Connell PR, editors, Bailey \& Love's Short practice of Surgery.26th ed.CRC Press:Taylor \& Francis Group, LLC. 2013:pp 948-69.

12 Schools IG, Van Dijkman B, Butzelaar RM, Van Geldere D, Simons MP. Inguinal hernia repair in Amsterdam region. Hernia. 2001;5:37 40

13 Gulzar MR, Iqbal J, Haq MI, Afzal M. Darning versus Bassini repair for inguinal hernia. Professional Med J. 2007;14:128-33.

14 Pabinger I, Fries D, Schöchl H, Streif W, Toller W. Tranexamic acid for treatment and prophylaxis of bleeding and hyperfi brinolysis Wiener klinische Wochenschrift . 2017 May 1;129(9- 10):303-16

15 Ahmed MR, Sayed Ahmed WA, Madny EH, Arafa AM, Said MM. Effi cacy of tranexamic acid in decreasing blood loss in elective caesarean delivery. Th e Journal of Maternal-Fetal \& Neonatal Medicine. 2015 Jun 13;28(9):1014-8

16 Ahmed H, Dawani S, Rasul S, Jafferi S. Seroma reduction and role of tranexamic acid in ventral hernia repair. J Surg Pakistan. 2020;25 (2):89-92. Doi:10.21699/jsp.25.2.9.
17 Spotnitz WD. Fibrin Sealant: The Only Approved Hemostat, Sealant, and Adhesive-a Laboratory and Clinical Perspective. ISRN Surg 2014;2014:203943. Published 2014 Mar 4.

18 Ausen K, Fossmark R, Spigset O. Randomized clinical trial of topical tranexamic acid after reduction mammoplasty. $\mathrm{Br} J$ Surg 2015;102(11):1348-53.

19 Rabbia Zubair, Masoom Raza Mirza, Lubna Habib, Javeria Ift ikhar, Batool Zehra. Role of tranexamic acid in prevention of seroma formation aft er ventral hernioplasty. Pak J Surg 2020; 36(2):126-129

20 Ahmed H, Dawani S, Rasul S, Jafferi S. Seroma reduction and role of tranexamic acid in ventral hernia repair. J Surg Pakistan 2020;25 (2):89-92. 18. Eldesouky MS, Abo Ashour HS, Shahin MA. Effect of topical application of tranexamic acid on reduction of wound drainage and seroma formation after mastectomy. Egypt J Surg 2019;38:7725 .

21 Eldesouky MS, Abo Ashour HS, Shahin MA. Effect of topical application of tranexamic acid on reduction of wound drainage and seroma formation after mastectomy. Egypt J Surg 2019;38:772-5. 